\title{
АКТУАЛЬНАЯ ТЕМА
}

УДК 378.126

doi: $10.11621 /$ vsp.2017.03.03

\section{ПРЕПОДАВАТЕЛЬ ОТЕЧЕСТВЕННОГО ВУЗА ПЕРЕД ВЫЗОВАМИ СОВРЕМЕННОСТИ}

\section{Н. Д. Творогова, В. А. Кулешов}

Вступление России в Европейское образовательное пространство (Болонский процесс) сделало актуальными инновационные изменения в организации образовательного процесса в отечественных вузах. В статье поднимаются вопросы, касающиеся сложного положения преподавателя в условиях перестройки вузовской жизни, его здоровья и субъективного благополучия, производительности и качества его труда. Приводятся аргументы в пользу того, что инновационная образовательная деятельность увеличивает не только временны́, физические, профессиональные, социальные нагрузки на преподавателя, но и нагрузки на его личность; труд преподавателя в этих условиях становится все более высокотехнологичным, требующим большой интеллектуальной и эмоциональной отдачи. Авторы предлагают рассматривать индикаторы субъективного благополучия (соматического, психического, социального, духовного) участников учебно-воспитательного процесса как одну из целевых функций разработки педагогических технологий и один из показателей эффективности педагогической деятельности. В статье подробно освещаются такие факторы производительности преподавательского труда, как автоматизация учебного процесса и управление деятельностью преподавателей. Авторы отмечают, что автоматизация учебного процесса за счет использования

Творогова Надежда Дмитриевна - доктор психологических наук, профессор, зав. кафедрой педагогики и медицинской психологии, руководитель отделения «Клиническая психология» 1 МГМУ имени И.М. Сеченова (Москва). E-mail: n.tvorogova@gmail.com

Кулешов Владимир Аркадьевич - доктор технических наук, профессор кафедры информатики Государственного университета по землеустройству (Москва).E-mail: kuleshov.psi@gmail.com

ISSN 0137-0936 (Print) / ISSN 2309-9852 (Online) 
сложных форм искусственного интеллекта возможна только с опорой на тот интеллектуальный потенциал, который создан предыдущими поколениями вузовских преподавателей и ученых. Проводится мысль о необходимости сбережения преподавательских кадров вузов и об особой ответственности вузовского менеджмента за создание условий для творческой самореализации педагогических кадров. В качестве одного из направлений работы вузовского менеджмента анализируются организация и проведение периодической аттестации преподавателей. Делается акцент на значимость непрерывной профессиональной подготовки преподавателей высшей школы и менеджеров образования.

Ключевые слова: инновационный вуз, автоматизация учебного процесса, качество преподавательской деятельности, преподаватель как ценность образовательной системы, аттестация преподавателей, система управления качеством образования.

\section{Введение}

Вступление России в общее Европейское образовательное пространство (Болонский процесс) потребовало унификации процессов гарантии качества предоставляемых образовательных услуг, в связи с чем внедряется и во многих вузах РФ уже функционирует система менеджмента качества (СМК на основе ГОСТ РИСО 9001-2008), ставшая с 1 января 2006 г. обязательным аккредитационным показателем работы учебного заведения РФ. Каждый вуз подтвердил, что основой обеспечения его жизнедеятельности и развития является повышение качества образовательных услуг.

Качество образовательных услуг зависит от многих факторов, однако основным реализатором процесса обучения остается преподаватель. На повестке дня создание общеевропейской системы подготовки преподавателей вузов и их аккредитации.

Предъявление требований к преподавателю при оценке эффективности его труда, на наш взгляд, необходимо связывать не только с социальной значимостью этого труда, но и с теми условиями, в которых преподаватели в настоящее время находятся.

Чтобы оставаться в сфере реальности, а не иллюзий и мечтаний, общество не должно предъявлять требований преподавателю, не слыша его ответных требований; необходим общественный договор, оценка условий, ресурсов, которые общество, вуз могут и хотят предоставить преподавателю высшей школы. Так, в настоящее время годовая учебная (аудиторная) нагрузка преподавателя отечественного вуза более чем в 4 раза выше, чем у его коллеги из 
Евросоюза, а зарплата более чем в 7-10 раз ниже. Чтобы выживать, отечественному преподавателю приходится работать на 1,5 ставки (иногда в разных учреждениях), постоянно искать возможность приработка, что не может не сказаться на качестве педагогического труда, на здоровье, самочувствии преподавателя, удовлетворенности им своим трудом (Гульяец, 2003). Эмпирическое исследование субъективного социального благополучия 60 преподавателей четырех московских вузов в возрасте от 30 до 40 лет (30 женщин, 30 мужчин) выявило следующее распределение опрошенных преподавателей по уровням субъективного социального благополучия: по 5\% с высоким и низким уровнями, 10\% - скорее с высоким, $15 \%$ - со средним, 65\% - скорее с низким (Бовина, 2007).

Сказанное выше не отменяет необходимости поэтапного предъявления преподавателю отечественных вузов европейских требований при их аттестации. Однако на данном этапе отечественной вузовской жизни, по нашему мнению, более актуальна задача сбережения оставшихся в вузе опытных и талантливых преподавателей без дискриминации их по возрасту.

Преподавателям приходится слышать от высокопоставленных чиновников, что они (преподаватели) неэффективны (если получают такие низкие зарплаты), что их производительность труда ниже, чем у их коллег из стран Европейского союза, что они получают то, что заслужили. И действительно, производительность отечественных преподавателей ниже. Но кто ответственен за это: сами преподаватели или менеджмент, который управляет образованием? Даже поверхностный взгляд позволяет констатировать: отечественные преподаватели работают больше, чем их западные коллеги, их учебная нагрузка значительно выше, а научные достижения не ниже (отечественная высшая школа всегда славилась своими научными достижениями).

И все-таки, что делать с производительностью и качеством труда преподавателя, как их повысить? Ответ на этот вопрос - цель специальных исследований, которые проводятся в контексте изучения менеджмента высшей школы. Далее мы рассмотрим такие факторы производительности труда преподавателя, как автоматизация учебного процесса и управление деятельностью преподавателей.

Автоматизация учебного процесса. Создание и постоянное совершенствование автоматизированной системы образовательного пространства университета позволяет повысить производительность труда преподавателей и качество образовательных 
услуг (Кулешов, 2014). Одна из центральных причин нынешней низкой производительности труда не в том, что отечественные преподаватели ленивы и не хотят работать, а скорее в том, что образование в значительной степени является продуктом «ручного» труда (перегруженных и низкооплачиваемых преподавателей). Известный по советским временам путь стахановского движения (т.е. повышение производительности в рамках ручного труда) ведет в тупик.

А. Кудрин (будучи министром финансов) заявлял: без повышения производительности труда преподавателей не может идти речи о повышении их зарплат и снижении аудиторных нагрузок. Заметим, что без снижения аудиторной нагрузки преподаватель просто лишен возможности реально заниматься методической работой, наукой и учить студентов на уровне современных научных достижений, разрабатывать компьютерные обучающие программы. Путь автоматизации, по которому успешно идет университетское образование индустриально развитых стран, приводит к повышению качества образования через существенное снижение аудиторной нагрузки преподавателя вуза (примерно до 170 контактных часов в год), к повышению его зарплаты, способствует повышению качества выполняемой им научной и научно-методической работы.

Smart-образование строится на технологических инновациях, одной из его составляющих является электронное обучение (ЭО). В США более $90 \%$ вузов, школ и крупных компаний используют ЭО; для 65\% вузов Европы ЭО является важнейшим ресурсом (всю оболочку автоматизированной системы в обычном европейском университете обслуживают всего несколько человек). К причинам обращения к технологиям ЭО относят (Соловьев и др., 2014): a) улучшение качества образования, б) повышение эффективности образовательного процесса, в) увеличение объема оказываемых образовательных услуг без наращивания площадей и инфраструктуры, г) это способ расширить рынок без существенных дополнительных затрат. При ЭО более высокие требования предъявляются и к способностям студентов, к умению заниматься самоподготовкой, что немаловажно для современного специалиста.

Что такое автоматизация образовательного пространства? Это “железо” (как иногда называют ее техническое обеспечение компьютеры и различные цифровые устройства, интернет и пр.) и “софт" (как именуют программное обеспечение).

Начальный шаг автоматизации многими нашими университетами давно взят на вооружение. В ведущих в этом направлении 
отечественных вузах оборудуются интерактивные лекционные аудитории, используются дистанционные образовательные технологии в заочной форме обучения, разрабатываются интерактивные образовательные видеоматериалы, электронные библиотечные системы, контенты (производители контента конкурируют между собой за внимание потребителя), виртуальные лабораторные комплексы, электронные системы учета учебных достижений студентов и пр. (Творогова и др., 2008).

Примеры отечественных ЭО: информационные системы «Единое окно доступа к образовательным ресурсам», лекции ведущих лекторов России, открытый виртуальный университет, записи вебинаров, массовые открытые дистанционные курсы (MOOC) и пр. Учебные заведения имеют право бесплатно использовать в своем учебном процессе курсы (оформлены как электронная библиотека), например разработанные негосударственным образовательным учреждением Национальный открытый университет «Интуит». В 2014 г. начал работать еще один российский проект, занимающийся МООС «Универсариум» (миссия проекта - предоставление миллионам российских граждан возможности получить качественное образование от лучших российских преподавателей и ведущих университетов), курсы и образовательные программы которого создаются совместно с лучшими преподавателями ведущих вузов страны, вошедших в проект.

В настоящий период на повестке дня - массовая разработка обучающих компьютерных программ для учебных дисциплин, включенных в учебные планы специальностей, которые осваиваются в вузе студентами разных факультетов. Однако для использования оборудования, которое в отечественных вузах уже имеется, необходима большая подготовительная работа (которая, впрочем, к 1980-м гг. была проделана отечественными преподавателями, занимающимися оптимизацией учебного процесса; однако наступили 1990-е гг, и отечественное образование стало вписываться в европейское образовательное пространство, отвернувшись от многих своих ранее достигнутых успехов). Чтобы включить новое поколение преподавателей при их большой учебной нагрузке в процесс автоматизации учебного процесса, требующий большой компетентности и большой подготовительной работы, только приказа руководителя вуза уже недостаточно. Необходимо готовить новых менеджеров, которые будут способны внести инновационные изменения не только в сам учебный процесс, но и в его организацию. 


\section{Инновационный вуз и менеджмент «с человеческим лицом»}

Для вуза, реализующего стратегию инновационного развития, важно заявить о своих намерениях, поскольку суть лидерской позиции его руководителя состоит в опережении времени. Подчас успешные руководители делают то, что в настоящее время большинству сотрудников кажется невозможным, но их активность поддерживается верой в лучшее, стремлением к высоким целям. Миссия, Видение и Ценности - фундамент, на котором строится политика, структура, инновационное развитие организации. Понимание движения организации в будущее создает основу для формирования индивидуальных и групповых ожиданий ее сотрудников и партнеров, создает основу для ее предсказуемости, надежности в общении с ней. За декларацией о намерениях начинается длительная и кропотливая работа в направлении того, чтобы реальность все более приближалась к заявленным ожиданиям (Творогова, 2007).

Согласно К. Левину, организационные изменения происходят в три этапа: создание готовности к изменениям, переход и закрепление. Скорость вузовских изменений связывают с темпом развития восприимчивости преподавателей, других сотрудников, с темпом накопления их знаний, умений и навыков, с формированием у них новых ценностных ориентаций. В структуре психологической готовности преподавателей к реализации инновационных образовательных программ выделяют когнитивную и личностную готовность (Психолого-педагогическое сопровождение..., 2007). Преподаватель должен знать цели и задачи, стоящие перед вузом (факультетом, кафедрой), ориентироваться в личных интересах и целях своих учащихся, осознавать свои ценности и личные цели, чтобы все это направлять в единое русло. При традииионной стратегии организации образования преподаватель должен был (а) знать предмет, который преподает, (б) владеть принятой на данный период методикой преподавания, (в) уметь проводить воспитательные мероприятия по плану кафедры (факультета, вуза), (г) уметь вести тот или иной раздел (фрагмент) кафедральной документации, (д) владеть техническими средствами обучения, (е) прочее. Инновационная стратегия организации образования не устраняет значения всего перечисленного выше; в то же время она вносит свои акценты. Так, в настоящее время от каждого преподавателя требуется не только планировать свою работу и отчитываться о ней, делать записи в ка- 
федральных журналах о проведенных занятиях, писать рецензии и отзывы на студенческие работы, но и стать соучастником новой управленческой технологии - системы менеджмента качества (которая не сводится к документообороту).

Система менеджмента качества (СМК) (ГОСТ РИСО 90012001) - часть системы менеджмента вуза; ее цель - улучшение деятельности организации, обеспечение удовлетворенности потребителей и других заинтересованных сторон. Функционирование СМК зависит от: а) уровня развития вуза (возможности вуза - его способности обеспечивать результаты образовательного процесса, которые соответствуют требованиям к ним); б) финансирования вуза, его образовательного процесса; в) рентабельности вуза; г) др.

Менеджер образовательного учреждения - центральная фигура в обеспечении СМК; о рядовых преподавателях в документах упоминается мало, хотя среди принципов менеджмента качества можно увидеть и принцип вовлечения работников, поскольку основная тяжесть в реализации СМК ложится на плечи преподавателей, реализующих учебный процесс и обеспечивающих его качество. Предполагается, что преподаватель не только будет выявлять проблемы вузовской жизни, участвовать в принятии решения по этим проблемам, но и явится активным проводником принятых решений в жизнь, будет соучаствовать в контроле за их исполнением. Для выполнения этих функций в настоящее время говорят о необходимости готовить преподавателей новой формации, ведущих исследовательскую деятельность на мировом уровне, разрабатывающих автоматизированные технологии преподавания, ориентированные на формирование и развитие навыков и компетенций, необходимых для инновационной деятельности.

Инновационная стратегия организации образования требует изменения привычного уклада профессиональной жизни каждого преподавателя (однако, как писал великий Иван Павлов, смена динамического стереотипа сопровождается отрицательными эмоциями), поэтому отношение вузовских преподавателей к любым инновациям различно: они либо способствуют организационным изменениям, либо препятствуют им, либо занимают позицию «стороннего наблюдателя» (преподавателю нельзя что-то навязать, он должен быть вовлечен в процесс, понимать его смысл для себя и для дела, которому он служит). Поскольку от преподавателя ожидается активная позиция, социально-психологическое обеспечение топменеджерами вуза инновационных процессов предполагает: 
(1) учет установок, ценностных ориентаций, моральных норм, интересов различных участников нововведений;

(2) использование социально-психологической информации для разработки мер функционального, организационного, экономического, коммуникативного обеспечения нововведений;

(3) применение социально-психологических методов активного обучения работников и привлечения их к участию в нововведении; основная цель - формирование психологической готовности сотрудников к нововведению.

Сегодня преподаватель чувствует себя скорее волонтером, дарителем блага, не принимая навязываемую ему роль мелкого низкооплачиваемого наемного работника вуза, обеспечивающего уже преимущественно ставшие платными образовательные услуги, которые работодатель предлагает населению. Вузовский менеджмент должен учитывать эти реалии, особенности самосознания и самоопределения отечественного преподавателя.

При инновационной стратегии организации образования в средства достижения цели (на которую должны быть направлены все звенья учебно-воспитательного процесса, все усилия его исполнителей) включаются и личные качества управленческого, педагогического и другого персонала вуза. Если раньше такое включение человеческого потенциала, личностных качеств сотрудников в их профессиональную деятельность осуществлялось стихийно, то теперь это становится частью осознанного и рационального использования «человеческого фактора», который рассматривается как один из основных факторов, определяющих качество деятельности образовательного учреждения. Инновационная образовательная деятельность увеличивает не только временны́е, физические, профессиональные, социальные нагрузки на преподавателя, но и нагрузки на его личность; труд преподавателя в этих условиях становится все больше высокотехнологичным, требующим большой интеллектуальной, эмоциональной отдачи.

Инновационная деятельность в вузе, предполагающая активное использование личностного потенциала преподавателей, сотрудников, студентов должна способствовать их удовлетворенности соответственно работой, обучением в вузе. Гуманистический аспект взаимоотношений субъектов образования берется из формулы категорического императива И. Канта, провозглашающего каждого человека целью в себе и не допускающего превращения его в средство для других. Говоря «человек есть цель образования», понимают под этим помощь в его саморазвитии, удовлетворении 
его потребностей, развитии способностей, становлении как профессионала. Инновационная деятельность вуза не должна стать непосильной нагрузкой на преподавателей, сотрудников вуза, его менеджеров (когда нагрузка чрезмерна, человек вообще перестает что-либо делать - ведь «все равно всего не переделаешь»), она задумана как сфера самореализации преподавателя, раскрытия им своего неповторимого потенциала, призвана стать источником его профессиональной творческой активности. В атмосфере творчества раскрепощенные преподаватели, работающие в единой команде, действительно смогут создавать условия не только для собственного саморазвития, но и главное для развития личности своих учащихся. Вот тогда на смену авторитарному образованию и придет педагогика сотрудничества. Но для этого преподаватели должны быть вовлечены в процесс принятия решений, должны видеть, что от их мнения многое зависит на кафедре, в вузе, в отрасли, что с их мнением считаются и что их труд достойно оценивается обществом.

Имея в центре внимания студента (уровень его профессиональной компетентности, возможность самореализации через учебный процесс и пр.), менеджменту вуза необходимо не забывать и о преподавателях, не только об их профессиональной компетентности (учитываемой при приеме на работу и последующей периодической аттестации), но и о качестве их профессиональной жизни, уровне их здоровья. Иными словами, заботиться не только о предупреждении и лечении имеющихся у них болезней, периодической диспансеризации, но и об их здоровье как состоянии физического, психологического и социального благополучия; это определение здоровья записано в Уставе Всемирной организации здравоохранения (ВО3) еще в 1948 г. Действительно, кто как не преподаватель, должен разрабатывать и практиковать новые технологии в образовательном процессе, в частности обеспечивать автоматизацию учебного процесса, используя те технические средства, которые имеются в вузе?

В настоящий период в Национальной доктрине образования в РФ и Федеральной целевой программе развития образования на 2016-2020 гг. в качестве ведущих выделяются задачи сохранения здоровья, разработки здоровьесберегающих технологий обучения и формирования ценности здоровья и здорового образа жизни. Индикаторы субъективного благополучия (соматического, психического, социального, духовного) (Творогова, 2016) участников учебно-воспитательного процесса рассматриваются нами как одна из целевых функиий разработки педагогических технологий, как 
один из показателей эффективности педагогической деятельности. Операциональное определение этого показателя качества образования требует, на наш взгляд, оценки того, способствует ли процесс обучения в конкретном учебном заведении (на конкретной кафедре, у конкретного преподавателя) поддержанию у учащихся: (а) высокого уровня самоценности и принятия себя; (б) личностного роста, психологической интеграции и самоактуализации, самореализации (в учебной, профессиональной и общественной деятельности); (в) личностной автономии, перехода к самообучению и самовоспитанию; (г) адекватного отношения к результатам своей деятельности (успехам и неудачам); (д) навыков управления своим поведением с учетом с социальных норм и правил; (е) способности быть успешным, открытым переменам; (ж) целостной картины мира, на которую следует ориентироваться в своем поведении, чтобы быть успешным. Учебно-образовательный процесс должен создавать условия для социального успеха, повышения коммуникативной компетентности, представлений о системе профессиональной и социальной деятельности выпускника учебного заведения, системных представлений о структуре современного общества.

При оценке качества подготовки специалистов из-за усиления фактора динамизма и неопределенности предстоящей профессиональной жизни вместо традиционной ориентации на оценку знаний, умений, навыков все чаще используется критерий компетентности. Компетентность специалиста - это проявленные им на практике стремление и способность (готовность) реализовать свой потенциал (знания, умения, опыт, личностные качества и др.) для успешной творческой (продуктивной) деятельности в профессиональной и социальной сфере, осознавая социальную значимость и личную ответственность за результаты этой деятельности, необходимость ее постоянного совершенствования.

Состояниеблагополучия нетолько студентов, но и профессорскопреподавательского состава важно для приобретения студентами качественного образования. Состояние, в котором находится преподаватель, влияет на его работоспособность, под которой понимают (Филиппов, 1990): (1) способность человека развить максимум энергии и, экономно расходуя ее, достичь поставленной цели при качественном выполнении умственной и физической работы; (2) свойство, характеризующее способность человека выполнять определенную работу с требуемым качеством в течение заданного интервала времени (ГОСТ 26387-84); (3) тот максимум работы, который в состоянии выполнить человек. Работоспособность обеспе- 
чивается оптимальным состоянием различных физиологических систем организма при синхронной, скоординированной деятельности; физическая работоспособность нередко используется как мерило соматического здоровья человека. Пребывая в хорошем настроении, люди начинают проявлять особую общественную активность, стремятся завязать новые знакомства, хотят быть полезными другим и найти занятия в свободное время. Качество жизни преподавателя (ВО3 характеризует качество жизни как восприятие индивидами их положения в жизни в контексте культуры и системы ценностей, в которых они живут, в соответствии с их целями, ожиданиями, стандартами и заботами) сказывается на его соматическом здоровье, работоспособности, удовлетворенности жизнью и поэтому должно быть в центре внимания менеджеров вуза.

Уровень здоровья участников образовательного процесса (увеличение потенциала здоровья здоровых лиц) должен стать косвенным индикатором и качества вузовского менеджмента. Выбор управленческой парадигмы менеджерами образования не должен, на наш взгляд, останавливаться на приемах, способствующих хронизации дистресса преподавателей, управлять их профессиональным поведением преимущественно за счет нагнетания страха, чувства вины и пр. Важно культивировать корпоративную культуру образовательного учреждения, рассматривающую в качестве основных ценностей не только реализацию Государственных образовательных стандартов, но и психологическое благополучие участников учебно-воспитательного процесса. Особенности организационной культуры вуза влияют на:

- социально-психологический климат в нем (так, число и качество конфликтов в организации, рассматриваемых как вид «климатических возмущений», зависит кроме прочих факторов и от особенностей ее культуры, характера взаимодействия субкультур);

- эффективность труда сотрудников вуза: (а) организации, в которых ценятся инновации, делается акцент на успех и высокие персональные достижения персонала, поощряется самостоятельность и активность в сочетании с командными формами труда, способствуют росту эффективности отдельного сотрудника, рабочей команды; (б) организации, ценности которых исчерпываются достижениями производственно-экономических целей, обычно оказываются в худшем финансовом положении;

- стиль делового общения сотрудников, их имидж; 
- уровень ощущения психического и социального благополучия (что в свою очередь влияет на соматическое и психическое здоровье сотрудников вуза).

Отечественные вузы имеют многовековую историю, накопили богатые традиции, выработали специфические ритуалы, славятся своими героями. В то же время переход нашей страны из советской эпохи в новые социальные и экономические реалии требует не только уважения к отечественной культуре, но и разумной трансформации организационной культуры (управление этой трансформацией). Эту работу должны возглавлять вузовские менеджеры, что скажется на состоянии участников учебно-воспитательного процесса, будет способствовать повышению производительности труда профессорско-преподавательского состава вуза.

Одно из направлений работы вузовского менеджмента организация и проведение периодической аттестации преподавателей.

\section{Аттестация преподавателей в контексте системы управления качеством образования}

Идея аттестации (оценки) специалиста, его профессиональной успешности - не изобретение нашего времени; испытание индивидуальных способностей - важная часть общественной жизни многих народов со времен древнейших цивилизаций до наших дней (Аксенова, 1999).

Аттестация определяется как комплексная оценка уровня квалификации, профессионализма и продуктивности деятельности работников государственных и муниципальных образовательных учреждений; оценка формализована (задана определенная методика), стандартизирована (применяются эмпирические методы) и институционализирована (заданы цели, задачи, частота и последствия аттестации специалиста). Аттестация призвана определить профессиональное соответствие специалиста занимаемой должности (понятия «профессиональная квалификация» и «должностные обязанности» не тождественны). Основными принципами аттестации согласно «Типовому положению об аттестации педагогических и руководящих работников государственных, муниципальных учреждений и организаций образования Российской Федерации» являются добровольность, открытость, коллегиальность, социальная и правовая защищенность, обеспечивающие объективность, гуманное и доброжелательное отношение к специалистам. 
Аттестация не самоцель, ее главное предназначение - стимулирование профессионального развития и совершенствование деятельности работников (Новиков и др., 2012). Методику аттестации можно было бы свести лишь к оценке успешности специалиста, если бы аттестация не рассматривалась как фактор его профессионального роста и непрерывного постдипломного образования (кроме стимулирования профессионализма и развития творческой инициативы целями аттестации провозглашаются также и обеспечение социальной защищенности работников в условиях рыночных отношений, и обеспечение социальной справедливости путем дифференциации оплаты труда) (Кудрявая, Зорин, 2004).

Предполагается, что методика и процедура аттестации вариативны, чтобы аттестуемый имел возможность выбора способа оценки качества его деятельности; аттестацию необходимо проектировать с учетом психологии взрослого человека; ее проведение не должно приводить к стрессам и нервным потрясениям (Зеер, 2008). В зарубежных аттестационных системах проводится оценка как результатов труда, так и потенциала сотрудника (Schafer, 1985); для бюрократической же структуры важна оценка работников только в соответствии с требованиями руководства (Аксенова, 1999).

Аттестация инициирует обратную связь между руководителем и сотрудниками; сотрудники должны доверять руководителю, аттестационной комиссии, считать результаты аттестации объективными и справедливыми. Однако как можно сегодня считать справедливым, например, требование использовать механизмы оценки преподавателей с привлечением международного профессионального сообщества и с ориентацией на показатели публикационной активности в престижных зарубежных изданиях? И это в ситуации, когда введены международные секторальные экономические санкции в отношении РФ, при наличии разных научных школ, при отсутствии жестких корреляций между количеством публикаций и их научной ценностью, при необходимости преподавателю платить за публикацию своей работы в престижном журнале, а также в ситуации сокращения более чем в 30 раз (в сопоставимых суммах по сравнению с 1990 г.) выделяемых на вузовскую науку ежегодных бюджетных ассигнований (Егоршин, Гуськова, 2014). И почему автоматизацией учебного процесса преподаватель должен заниматься в «свободное от работы время» на общественных началах, не получая за этот значимый труд достойной оплаты? 
Процедура лицензирования и аккредитации вузов с 1995 г. постоянно усложняется и буквально «лихорадит» ректораты, деканаты, кафедры, рядовых преподавателей. Управленческая вертикаль требует перехода от мониторинга эффективности вузов к ежегодному мониторингу эффективности преподавателей вуза. Однако исследования профессора МГУ Н.Ф. Талызиной (1984) доказывают, что пошаговый контроль за деятельностью специалиста (надзор за ним) контрпродуктивен, не повышает, а снижает его производительность труда (такой контроль условно уместен по отношению к новичкам, только осваивающим какую-либо деятельность). Контроль - это составная часть управленческой системы; не создав преподавателю достойных условий для выполнения им своих должностных обязанностей и направив все административные усилия на контроль за ним, можно получить обратный эффект в отношении его производительности; такая стратегия не приведет к повышению качества учебного процесса (это то же самое, что игнорирование преподавателем процесса формирования у учащихся знаний и умений и сосредоточение внимания на процедурах зачета и экзамена).

\section{Заключение}

Преподаватель остается центральной фигурой в вузе (студентов обучает специалист в своем деле; все остальное, в том числе и компьютерные обучающие программы, - это средства обучения, которые использует преподаватель); и все службы вуза должны работать на создание условий для повышения производительности и качества его труда. По естественным причинам уходит образованное поколение советской вузовской интеллигенции, которая имела не только высокую профессиональную квалификацию, но и сформированную систему ценностей, направленную на поиск истины, служение профессии, людям, Отечеству; уходят сами или нередко изгоняются носители вузовских технологий обучения, отработанных в течение столетий. Стало уже общим моментом констатировать резкое ухудшение качества кадрового обеспечения отечественных вузов, качества преподавательского состава (может, стоит говорить о резком ухудшении менеджмента высшего образования, не учитывающего реалии, в которых находятся преподаватели, а посему деморализующего и вгоняющего в апатию еще пока сохраняющийся профессорско-преподавательский корпус высшей школы?). 
Автоматизация учебного процесса за счет использования сложных форм искусственного интеллекта, которая рано или поздно приведет к созданию компьютерного интеллектуального тьютора, настроенного на каждого обучающегося в отдельности с учетом его конкретных потребностей, возможна только с опорой на тот интеллектуальный потенциал, который создан предыдущими поколениями вузовских преподавателей и ученых (хотя внешне формы обучения будущего и прошлого контрастно различаются, но это только по форме).

Важно не игнорировать ценность еще оставшихся с прошлых времен специалистов, а всячески помогая им, терпеливо и настойчиво с их помощью выращивать будущее поколение вузовских преподавателей, которые захотят работать на благо нашей страны, ее народа. «Хорошая политика не отличается от хорошей морали» (афоризм Г. Мабли).

Сказанное выше, на наш взгляд, свидетельствует о значимости непрерывной профессиональной подготовки как преподавателей высшей школы, так и менеджеров образования.

\section{СПИСОК ЛИТЕРАТУРЫ}

Аксенова Е. Технологические аспекты проведения аттестации // Управление персоналом. 1999. № 2.С. 22-28.

Бескаравайная T. Не зарплатой единой // Газета российского врача «Медицинский вестник» от 29 мая 2015 г. С. 5.

Бовина И.Б. Социальная психология здоровья и болезни. М.: Аспект Пресс, 2007.

Гульяеи, С.С. Использование социально-психологических методов для оценки качества жизни населения // 3-я Российская конференция по экологической психологии (Москва, 15-17 сентября 2003 г.): Тезисы. М.: ПИ РАО, 2003. С. $313-316$.

Егоршин А.П., Гуськова И.В. Высшее образование в России: достижения, проблемы, перспективы // Высшее образование в России. 2014. № 6 (14). C. $14-21$.

Зеер Э.Ф. Психология профессий. М.: Академический проект; Фонд «Мир», 2008.

Кудрявая Н.В., Зорин К.В. Потеря смысла жизни как духовно-нравственный и медико-психологический феномен // Смысл жизни и акме: 10 лет поиска: В 2 т. / Под ред. В.Э. Чудновского, А.А. Бодалева и др. М.: Смысл, 2004. Т. 2. C. $3-15$.

Кулешов В.А. Автоматизация образовательного пространства в государственном университете по землеустройству // Землеустройство, земельный кадастр и мониторинг земель. 2014. № 6. С. 72-80. 
Новиков А.И., Водолазский Н.Б., Творогова Н.Д. Современные подходы к обучению в течение жизни в профессии преподавателей медицинских вузов. Омск: ООО «Полиграфический центр КАН», 2012.

Орлов Ю.М., Данилин Е.Н., Каган В.И. Проблема эффективности в обучении и некоторые методические подходы к ее оценке в медвузе // Вопросы повышения эффективности и качества обучения в медицинском вузе / Под ред. И.А. Сыченникова. М.: Изд-во 1 ММИ им. И.М. Сеченова, 1978. С. 83-95.

Психолого-педагогическое сопровождение реализации инновационных образовательных программ / Под ред. Ю.П. Зинченко, И.А. Володарской. М.: Изд-во Моск. ун-та, 2007.

Соловъев М.А., Качин С.И., Велединская С.Б., Дорофеева М.Ю. Стратегии развития электронного обучения в техническом вузе // Высшее образование в России. 2014. № 6 (14). С. 67-76.

Тальзина Н.Ф. Управление процессом усвоения знаний: Психологические основы. М.: Изд-во Моск. ун-та, 1984.

Творогова Н.Д. Психология управления. 2-е изд. М.: ГЭОТАР-Медиа, 2007.

Творогова Н.Д. Благополучие субъективное // Клиническая психология: энциклопедический словарь / Под общ. ред. проф. Н.Д. Твороговой. 2-е изд., перераб. и доп. М.: Практическая медицина, 2016. С. 111-112.

Творогова Н.Д., Мыльников А.В., Сидельников К.В. Психологопедагогические требования к учебным материалам для дистанционного обучения врачей общей практики // Вестник семейной медицины. 2008. № 7. С. $68-69$.

Филиппов А.В. Работа с кадрами: психологический аспект. М.: Экономика, 1990.

Schäfer P. Personalbeurteilung und Beurteilungssysteme im öffentlichen Dienst, Hochschule für Verwaltungswissenschaften. Speyer, Deutschland: Springer-Verlag, 1985. 


\title{
LECTURER AT DOMESTIC UNIVERSITY FACING THE CHALLENGES OF OUR TIME
}

\author{
Nadezhda D. Tvorogova ${ }^{1}$, Vladimir A. Kuleshov ${ }^{2}$ \\ ${ }^{1}$ I.M. Sechenov First Moscow State Medical University, Moscow, Russia \\ 2 State University of Land Use Planning, Moscow, Russia
}

\begin{abstract}
Russia joined the European Higher Education Area (Bologna process), that made innovative changes in the organization of educational process in Russian universities an urgent issue. The article raises questions concerning the difficult position of the lecturer in the context of the restructuring of university life, the lecturer's health and subjective well-being, productivity and quality of his work. It is argued, that innovative educational activity increases not only time, physical, professional, social load for the lecturer, but as well the load on his personality; the work of the lecturer in these conditions is becoming increasingly high-tech, requiring great intellectual and emotional engagement. The authors propose to consider the indicators of subjective well-being (somatic, mental, social, spiritual) of the educational process participants as one of the objective functions of pedagogical technologies development and as one of the indicators of pedagogical activity efficiency. The article covers in detail such factors of the productivity lecturers' work as educational process automation and lecturers' activity management. The authors note that the educational process automation through the use of complex forms of artificial intelligence is possible only if it is based on the intellectual potential created by previous generations of university lecturers and scientists. The idea is suggested about the need to save the teaching staff of universities and about the special responsibility of university management for developing the conditions for creative self-realization of teaching personnel. The organization and periodic certification of lecturers is analyzed as one of the areas of university management. The emphasis is placed on the importance of lifelong professional training of high school lecturers and education managers.
\end{abstract}

Key words: innovative university, automation of educational process, quality of teaching activity, the lecturer as a value of educational system, certification of lecturers, the management system of education quality.

\section{References:}

Aksenova, E. (1999). Tekhnologicheskie aspekty provedeniya attestatsii. Upravlenie personalom [Personnel Management], 2, 22-28.

Beskaravaynaya, T. (2015). Ne zarplatoy edinoy. Gazeta rossiyskogo vracha «Meditsinskiy vestnik» ot 29 maya $2015 \mathrm{~g}$. [The newspaper of the Russian doctor "Medical Bulletin" of May 29, 2015], 5. 
Bovina, I.B. (2007). Sotsial'naya psikhologiya zdorov'ya i bolezni [Social psychology of health and disease]. Moscow: Aspekt Press.

Egorshin, A.P., Gus'kova, I.V. (2014). Vysshee obrazovanie v Rossii: dostizheniya, problemy, perspektivy. Vysshee obrazovanie v Rossii [Higher education in Russia], $6(14), 14-21$.

Filippov, A.V. (1990). Rabota s kadrami: psikhologicheskiy aspekt. Moscow: Ekonomika, 1990.

Gul'yaets, S.S. (2003). Ispol'zovanie sotsial'no-psikhologicheskikh metodov dlya otsenki kachestva zhizni naseleniya. In: 3-ya Rossiyskaya konferentsiya po ekologicheskoy psikhologii (Moskva, 15-17 sentyabrya 2003 g.): Tezisy [3rd Russian Conference on Environmental Psychology (Moscow, September 15-17, 2003): Abstracts] (pp. 313-316). Moscow: PI RAO.

Kudryavaya, N.V., Zorin, K.V. (2004). Poterya smysla zhizni kak dukhovnonravstvennyy i mediko-psikhologicheskiy fenomen. In V.E. Chudnovsky, A.A. Bodalev and others (eds.) Smysl zhizni i akme: 10 let poiska: $v 2 t$. [The meaning of life and acme: 10 years of searching in 2 vol.] (Vol. 2, pp. 3-15). Moscow: Smysl.

Kuleshov, V.A. (2014). Avtomatizatsiya obrazovatel'nogo prostranstva v gosudarstvennom universitete po zemleustroystvu. Zemleustroystvo, zemel'nyy kadastr i monitoring zemel' [Land management, land cadaster and land monitoring], 6, 72-80.

Novikov, A.I., Vodolazskiy, N.B., Tvorogova, N.D. (2012). Sovremennye podkhody k obucheniyu $v$ techenie zhizni $v$ professii prepodavateley meditsinskikh vuzov [Modern approaches to lifelong learning in the profession of teachers of medical high schools]. Omsk: OOO «Poligraficheskiy tsentr KAN.

Orlov, Yu.M., Danilin, E.N., Kagan, V.I. (1978). Problema effektivnosti v obuchenii i nekotorye metodicheskie podkhody $\mathrm{k}$ ee otsenke $\mathrm{v}$ medvuze. In I.A. Sychennikov (ed.) Voprosy povysheniya effektivnosti i kachestva obucheniya $v$ meditsinskom vuze [The issues of increasing the efficiency and quality of education in a medical high school] (pp. 83-95). Moscow: Izd-vo 1 MMI im. I.M. Sechenova.

Schäfer, P. (1985). Personalbeurteilung und Beurteilungssysteme im öffentlichen Dienst, Hochschule für Verwaltungswissenschaften. Speyer, Deutschland: SpringerVerlag.

Solov'ev, M.A., Kachin, S.I., Veledinskaya, S.B., Dorofeeva, M.Yu. (2014). Strategii razvitiya elektronnogo obucheniya $\mathrm{v}$ tekhnicheskom vuze. Vysshee obrazovanie $v$ Rossii [Higher education in Russia], 6 (14), 67-76.

Talyzina, N.F. (1984). Upravlenie protsessom usvoeniya znaniy: Psikhologicheskie osnovy [Management of the learning process: The psychological basis]. Moscow: Izd-vo Mosk. un-ta.

Tvorogova, N.D. (2007). Psikhologiya upravleniya [Psychology of management]. 2-e izd. Moscow: GEOTAR-Media.

Tvorogova, N.D. (2016). Blagopoluchie sub"ektivnoe. In N.D. Tvorogova (Ed.) Klinicheskaya psikhologiya: entsiklopedicheskiy slovar' [Clinical Psychology: Encyclopedic Dictionary] (pp. 111-112). Moscow: Prakticheskaya meditsina. 
Tvorogova, N.D., Myl'nikov, A.V., Sidel'nikov, K.V. (2008). Psikhologo-pedagogicheskie trebovaniya k uchebnym materialam dlya distantsionnogo obucheniya vrachey obshchey praktiki. Vestnik semeynoy meditsiny [Family Medicine Bulletin], 7, 68-69.

Zeer, E.F. (2008). Psikhologiya professiy [Psychology of professions]. Moscow: Akademicheskiy proekt; Fond «Mir».

Zinchenko, Yu.P., Volodarskaya, I.A. (2007, Eds.) Psikhologo-pedagogicheskoe soprovozhdenie realizatsii innovatsionnykh obrazovatel'nykh programm [Psychological and pedagogical support of the implementation of innovative educational programs]. Moscow: Izd-vo Mosk. un-ta.

Original manuscript received September 15, 2017 Revised manuscript accepted September 26, 2017 